\title{
Do intentions and perceptions always meet? A case study regarding the use of a teacher appraisal scheme in an English language teaching environment
}

\author{
Ulker Vanci-Osam $^{\mathrm{a}, *}$, Tijen Aksit ${ }^{\mathrm{b}}$ \\ ${ }^{\text {a } F a c u l t y ~ o f ~ E d u c a t i o n, ~ M i d d l e ~ E a s t ~ T e c h n i c a l ~ U n i v e r s i t y, ~} 06531$ Ankara, Turkey \\ ${ }^{\mathrm{b}}$ School of English Language, Bilkent University, 06533 Ankara, Turkey
}

Received 7 August 1998; received in revised form 28 April 1999; accepted 21 June 1999

\begin{abstract}
This article reports research examining a group of English language teachers' perceptions of the teacher appraisal scheme with a developmental purpose. Specifically, the researchers tried to find out if there is a discrepancy between what the institution intended to achieve and how teachers perceived the scheme before and after their participation in it. The findings of the study, which were obtained by analysing the data collected from the teachers and appraisers in the form of two structured interviews revealed some significant clues for the institutions which are involved in or interested in running teacher appraisal schemes in their workplace. (C) 2000 Elsevier Science Ltd. All rights reserved.
\end{abstract}

Keywords: Teacher appraisal; Teacher development; English language teaching

The purpose of this article is to share with the reader the findings of a study conducted to discover a group of English language teachers' perceptions of the Teacher Appraisal Scheme (TAS), which has been launched in an English language school of a university in Ankara, Turkey.

It is true that the rapidly changing trends in English Language Teaching (ELT) methodology are requiring teachers to possess different characteristics. As O'Sullivan, Jones, and Reid (1988, p. 3) point out, teachers now are expected to adopt a philosophy of lifelong learning in their own

\footnotetext{
*Corresponding author. Tel.: +90-312-210-40-81; fax: + 90-312-210-12-56.

E-mail address: ulkos@tutor.fedu.metu.edu.tr (U. VanciOsam)
}

professional activities, which, in fact, supports the concepts of 'teacher development' (Woodward, 1991) and 'reflective model' for foreign language teacher training suggested by Wallace (1991). Similarly, Nunan (1993), and Brumfit and Mitchell (1993) note that like all the other practitioners in other fields, language teachers should always be engaging in research if they are to work responsibly and professionally. Professional development in ELT requires the efforts of not only the individual teachers but also the institutions. Clarke, Davis, Rhodes, and DeLott Baker (1998, p. 593) see effective instruction as an institutional accomplishment rather than as an individual tour de force. Similarly, England (1998) stresses the role of institutions in preparing teachers for the ELT profession. She says, "more and more, ELT employers will also 
have to provide professional development through in-service training" (p. 23), and ultimately ELT programs will benefit from teachers who are current with the field. In an institution where there is professional collegiality and educational leadership, new teachers, once hired, are usually oriented to the institution's mission, policies and procedures; career needs are determined; training programs are organised; formal performance appraisals are conducted periodically; measures are taken to retain and support those who are effective and efficient; and decisions are made to cater for these aims.

Among the numerous ways adopted by the ELT institutions to promote the professional development of teachers is the Teacher Appraisal Scheme (TAS). TAS was started in the USA in 1970s and in Britain in 1980s and has already become a significant educational issue in these countries. In fact, the origin of this scheme lies in areas other than education, where it is named 'Performance Appraisal' after the introduction of the Human Resource Management (HRM) in 1970s. In its broad sense, formal performance appraisal is a scheme followed to evaluate employee performance regularly and systematically. Randall, Packard and Slater (in Scribbins \& Walton, 1987, p. 29) see the principal aims of TAS as 'evaluating', 'auditing', 'constructing succession plans', 'changing jobs', 'discovering training needs', 'motivating staff', 'developing individuals' and 'checking the effectiveness of personnel procedures'. Therefore, TASs use data collected as a result of the assessment of teachers in an institution for one of the aims discussed above. Thus, one of the main advantages of performance appraisal is seen as the opportunity for both the employee and the employer to identify areas that the employer needs to improve as far as the institution's expectations of the employee are concerned, but what is more important is the employee's self-appraisal of his/her own strengths and weaknesses at work. As teachers in such a system are supposed to become more aware of these areas and feel themselves more responsible for their own professional development, they are more likely to be considered better at developing themselves in those areas. Inevitably, this is expected to help the institution provide better quality teaching. However, the teachers' attitudes towards TAS, in other words the way they perceive the whole scheme and whether they think this system really helps them develop themselves professionally, are the key elements for teachers when they are asked to participate in the scheme which has already been adopted by their institution. The teachers' perceptions of the scheme play a crucial role in the success of TAS since the teachers are the main agents of TAS, and participating in the scheme benefits both the teachers and the institution as far as both the teachers' selfprofessional development and the institutional improvements are concerned. Therefore, studying the teachers' perception of TAS is worthwhile, especially, if the participant teachers are the ones who are really not very familiar with such a concept, as is the case with most of the English language teachers in Turkey.

\section{Research context}

The study to be described in this article was conducted in an English Language School of a university in Ankara, which provides pre- and insessional English language courses. In fact, this ELT institution teaches over 2000 students and employs around 150 teachers. The teacher population in this institution is heterogeneous with regard to age, ELT experience, ELT qualification, and nationality. In order to enhance an efficient communication channel between the teachers and the management, teachers work in small groups which are led by 'group leaders'. Teacher training and development is a crucial issue for this institution, and there are actually some activities with these aims in operation, such as various certificate and diploma courses. Among these activities, TAS appears to be the latest one introduced to the teachers with the aim of professional development.

This scheme was introduced to the teachers via a briefing session which lasted four days. Teachers were informed on the general aims, principles and guidelines of the process during the sessions. Apart from this, each teacher received a handbook, which not only summarises all the issues discussed in the briefing but also contains all the necessary documents that teachers may need to actively 


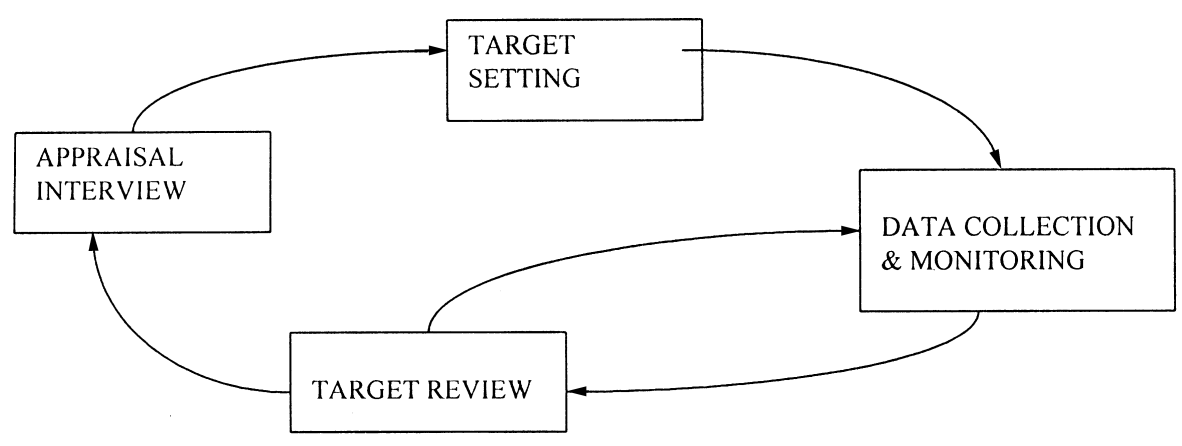

Fig. 1. One cycle of TAS.

participate in the TAS. In addition, teachers had access to a TAS Data Collection File, which provided them with various data collection instruments and ideas for preparing new ones.

Both the briefing session and the TAS handbook listed the general aims of TAS: (a) to facilitate the professional development of teachers, (b) to improve the quality of classroom performance, and (c) to better inform decision-making in the institution. Administrators of TAS also believed that an appraisal scheme would increase the scope for personal achievement, job satisfaction and career development.

In the process of TAS, which was managed by a group leader and which ran concurrently with the academic year, there were three main stages: (a) the target-setting meeting, (b) data collection and monitoring, and (c) a final appraisal meeting. However, this process can consist of as many of the cycles represented in Fig. 1 as possible in one academic year before the appraisal meeting, depending on the time period that a teacher needs to reach his/her target(s).

One teacher may complete one cycle while another can complete four or more cycles during two semesters. No matter how many cycles a teacher covers, each has his/her appraisal meeting, which is the third and the last stage of the whole process at the very end of the academic year.

The teacher can set any target he/she wishes. In the target setting meeting, he/she informs the group leader of the target(s). Target setting is seen as a part of a continuous and systematic process which helps teachers to identify areas to be developed in order to enhance their own effectiveness in, for example, teaching language skills or in classroom management. Targets are expected to allow teachers to examine their own performance in areas that they have evaluated and wish to realise improvement in or further develop. Therefore, target setting is about planning and controlling teachers' own development as teachers.

The next step is to collect data relevant to targets. The collected data should provide an accurate reflection of performance. Many ways to collect data relevant to the agreed targets are accepted. Classroom observation involving a range of different individuals (teacher's peer, who may be the group leader, teacher trainer, or any other colleague), and a variety of observation tools (audio or video recordings, evaluation checklists, diaries, logs, etc.) are among those suggested by the institution. As a result of the natural self-monitoring of the teachers' progress towards their target, they may need to discuss matters with their peers and possibly review the original target(s). Any changes to the targets are formalised in a Target Review Meeting with the group leader.

The final stage is the appraisal meeting, the aim of which is to review the work done on improving performance, evaluate the work the appraisee has carried out during the year, plan for the future, define any help needed and raise issues of concern.

\section{Research question}

As stated earlier, the TAS, in practice in the English Language School, had a developmental 
focus and aimed at developing the teaching staff professionally. Naturally, for such a system to achieve its aim and fulfil its purposes, the reaction and the attitudes of the teachers play a very important role. Therefore, we were interested in finding the answer to this question: "What is the perception of English language teachers of the Teacher Appraisal Scheme (TAS) in regard to its effectiveness in contributing to their professional development?"

We felt that in order to be able to answer this question, the following sub-questions also needed to be answered: (a) Is there a discrepancy between the ELT teachers' perception of TAS with a developmental purpose before and after their participation in a cycle of the scheme?, (b) Is there a relation between their perception and demographic data such as nationality, ELT experience, and ELT qualification? and (c) Is there a discrepancy between the teachers' (appraisees') and leader's (appraiser's) perceptions of TAS?

\section{Data collection and analysis}

We designed this study by following the principles of ethnographic tradition, which emphasises the importance of obtaining multiple perspectives through triangulation. Among a number of ethnographic approaches identified in Long (1980), this particular study employs both participant ethnography which involves the researcher(s) taking a regular part in the activities under study and non-participant ethnography, which uses a variety of data collection techniques: note-taking, interviewing, questionnaires, ratings of personal opinions, and written documents. Since we meant this research to be qualitative, with a descriptive role, as defined by Krathwohl (1998, p. 34), rather than quantitative, utmost care has been taken to meet the other requirements of a qualitative research stated in Fraenkel and Wallen (1993, pp. 380-381).

Since it was impractical to collect data from 150 teachers working in the institution, we selected one-third of the teacher population by a stratified sampling method. That is to say, before the actual sampling was carried out, we observed that the background characteristics of the teachers in the institution varied in terms of their nationality, ELT experience, and ELT qualifications ${ }^{1}$. As these three factors were important in finding an answer to our second pre-set research question, we assigned one stratum to a group of teachers who shared particular characteristics. In the end, the whole population was divided into seven strata: (1) Native English speakers without any ELT post-graduate qualifications (4 teachers in number), (2) Native English speakers with some sort of ELT post-graduate qualifications (CTEFLA - Certificate for Teachers of English as a Foreign Language, DTEFLA - Diploma for Teachers of English as a Foreign Language, MATEFL - Master of Arts in Teaching English as a Foreign Language, etc.) (6 in number), (3) Turkish teachers who have less than three years of experience and have completed COTE - Certificate for Overseas Teachers of English (4 in number), (4) Turkish teachers who have three to nine years of experience but have not got any postgraduate ELT qualification (8 in number), (5) Turkish teachers who have three to nine years of experience and have got a post-graduate ELT qualification (13 in number), 6) Turkish teachers who have more than 10 years of experience but no post-graduate ELT qualification (5 in number), and 7) Turkish teachers who have more than 10 years of experience and a post-graduate ELT qualification (10 in number). The strata for the native English speakers were not assigned according to their years of experience not only because all of them had more than three years of experience but also because they were already a smaller group in the whole population.

After the definition of the strata, we adopted proportionate sampling. That is to say, the number of teachers in the selected groups reflected the proportion of that group in the whole population. In contrast to common practice, we chose the actual subjects through purposeful sampling, rather than random sampling, as a purposeful sampling approach allows the researchers to reach the individuals who are likely to be 'information rich' or

\footnotetext{
${ }^{1}$ Other possible variables have not been assessed in the study because of various reasons. Gender, for example, was not taken as a variable at all, because the number of male teachers was significantly small to contrast their perception of TAS with the perception of female teachers.
} 
'key informants', as Wiersma (1995) suggests. We also gathered some information from some written official documents, including 'TAS Handbook', 'Interim Evaluation Report' (written by the appraisers) and 'TAS Briefing Report' (written by the appraisers). Moreover, in order to triangulate the other data collected, we interviewed four group leaders (appraisers) individually to collect data on how they thought their appraisees perceived TAS. We collected feedback from both the teachers and the group leaders twice; first at the beginning of the scheme and once more after the first cycle, which was after the first target review meeting.

In order to collect data on the teachers' perception of TAS, we prepared two separate sets of structured interview questions. Teachers answered the first set of questions to give feedback on their initial view of TAS, just after they were introduced to the system and just before the first cycle of TAS started (see Appendix A). Teachers answered the second set of interview questions within two weeks after their target review meeting with their appraisers (see Appendix B). During these structured interviews, the teachers provided data on their views after the completion of at least one cycle of their appraisal.

The questionnaires covered the main features and the relationships in TAS. The main areas we were interested in were 'Introduction to TAS (through TAS Briefing), 'Target Setting/Target Review', 'Completion of the Cycle', and the 'Outcomes'. Questions were mainly 'background and demographic questions', 'experience and behaviour questions', or 'opinion or values questions', according to Fraenkel and Wallen's (1993, p. 386) classification of interviewing questions. We first categorised all the data recorded on the answer sheets of the initial questionnaire and the structured interviews and then visually displayed it in the form of tables to ensure the easiest and most reliable analysis and interpretation possible.

As we analysed the subjects' responses to the questionnaire and interview questions, we found that certain words, phrases, patterns of behaviour, subjects' ways of thinking, and events appeared frequently and stood out. Therefore, we assigned some words or phrases to each question to repres- ent coding categories to sort the descriptive data collected. Once we coded and categorised the data, we measured the frequency of occurrence of the categories. We should note here that as we were interested in qualitative rather than quantitative nature of the data, we used terms like 'many', 'frequently', 'common', etc. while drawing generalisations in our analysis. After the completion of counting, we designed two-dimensional matrices to present the collected data in a form which could help us to draw valid conclusions. (Please see Appendix $C$ to follow how we analysed the responses given for Question 11 in Teachers' Interview as an example. $)^{2} \mathrm{We}$ followed the same procedures to analyse the data gathered from the appraisers through the 'TAS Briefing Report' and interviews. For triangulation purposes, we compared this data with the data from the teachers to see if there were similar ideas expressed.

Various authors offer suggestions to ensure validity and reliability of the instruments and procedure used to collect and interpret the data (Fraenkel \& Wallen, 1993; Wiersma, 1995; Goetz $\&$ LeCompte, 1984). For example, one of the researchers' being a teacher in the institution has helped in the interpretation of data; however, to avoid excessive subjectivity and to ensure reliability, two other colleagues confirmed the objectivity of the data listing and the data coding processes. These colleagues coded $25 \%$ of the documents and around $80-90 \%$ of those were coded with the same categories used by the researchers.

\section{Findings}

As stated above, the aim of this study was to find out the teachers' perceptions before and after their participation in TAS.

\footnotetext{
${ }^{2}$ Please note that in some cases one participant's response includes more than one coding category; therefore, they entered more than once in this table. That is the reason why the totals in some columns are more than the n's for the same column. The reason why we quantified the data to write in these matrices was that we did not want the interpretations to be researcher biased, as mentioned by Miles \& Huberman (1984, pp. 232-233).
} 


\subsection{Teachers' perceptions before their participation in TAS}

According to the results of the questionnaire administered at the beginning of the scheme (just after the TAS target setting meetings), both Turkish teachers and foreign teachers (i.e. native English speakers) preferred to work on 'classroom management', 'skills teaching', and 'error correction' as their first targets. Although working on these areas normally requires a type of observation, almost half of the teachers stated that their target would not involve a type of classroom observation. Other teachers who admitted that their targets would necessitate classroom observation, on the other hand, would prefer to be observed by a peer (rather than the group leader or a teacher trainer). The second most popular type of observation teachers were planning to have was self-observation through audio or video recording. It seems that teachers' demographic data, namely their nationality, ELT experience and ELT qualifications did not play any significant role when they were choosing a target and deciding whether to have a classroom observation or not.

Teachers stated more negative ideas than positive ideas about being involved in TAS. Almost all Turkish teachers with more than 10 years of ELT experience plus a kind of post-graduate ELT certification, and the ones with less than three years of experience plus a COTE expressed positive attitudes about being involved in TAS. The most commonly pointed out negative perceptions concerned the time-consuming nature of TAS and the heavy teacher workload at the institution. One teacher even said, "Why doesn't the school reduce our teaching load to save some time for this?" On the other hand, regardless of their demographic data, the majority of teachers expected positive changes in their teaching performance as a result of being involved in TAS. A Turkish teacher with three years' experience commented, "I felt I stopped doing something to further develop myself as a teacher after I finished COTE in my first year in teaching. Now I'm glad I'll do something for this aim".

The above data gathered from the initial questionnaire about the teachers' initial perception of
TAS seem to be parallel to the data found in the 'TAS Briefing Report' written by the appraisers as far as the general skeleton of the information is concerned. Appraisers wrote the 'TAS Briefing Report' just after they introduced the system to the teachers in the initial briefing sessions. In this report they included the feedback they had taken from the teachers and they added their perspective on how they thought the teachers welcomed the system, in other words teachers' initial reactions. Most of the session leaders felt that the teachers in their group were "quite positive, thinking that this system may help them improve their teaching". However, many session leaders also said, "There are a lot of teachers in my group who are worried about the time consuming nature of the system; they are not sure how they can cope with these on top of their teaching load". These and other points expressed in those reports corroborate the data collected from the teachers. There is only one point discussed in the reports quite often but which was not expressed by the teachers during the interviews. According to the reports, many teachers were not ready yet to carry on with such a system and they needed further training on how to conduct research, how to observe a lesson, etc.

\subsection{Teachers' perceptions after their participation} in $T A S$

The data gathered from the interviews held with the teachers after the completion of the first cycle of TAS can be summarised as follows:

\subsubsection{Teachers' perceptions concerning the introduction of TAS (TAS briefing)}

Except for a few Turkish teachers with many years of experience, teachers generally disliked the briefing sessions held in the beginning, and said, "They were too long, boring, and a waste of time". When we asked how an ideal briefing session should have been, many of them agreed that there should be a brief introduction of the idea and the explanation of the system by clarifying the real aims. This implies that despite the TAS briefing session, there were still many teachers who did not know the real purposes of the management in starting the scheme. 


\subsubsection{Teachers' perceptions concerning}

the target setting and target review meetings

Many Turkish teachers with various demographic data liked the target setting and target review meetings and described them "as relaxed, nice, friendly, comfortable and non-threatening within a positive atmosphere". The same group of teachers found their group leaders (appraisers) "encouraging, understanding and helpful". There were some other teachers especially with post-graduate ELT certificates who thought their appraisers were "not qualified enough to give help and guidance". Only a few teachers among the whole group expressed their concern of being steered by the group leader. An experienced native English speaker said, "I felt that my appraiser imposed an area which I was not interested in at all but I had to work on that not to have a conflict with him".

\subsubsection{Teachers' perceptions concerning \\ the outcomes of the system}

Teachers generally preferred TAS to any other teacher development activities since they thought TAS was individually directed, gave more autonomy to teachers and diminished the appraiser interference. However, some Turkish teachers with many years of experience believed that TAS had too high expectations and was difficult to realise. Some foreign teachers, similarly, found TAS not as flexible as it was supposed to be. The same teachers added that they experienced some improvement only through the target they had chosen themselves, not by the force of other people (e.g. group leader).

Teachers' perceptions of the aim of TAS did not seem to vary according to their demographic data. A big majority of teachers perceived the aim of TAS in the institution as "awareness raising, self-evaluation, self-improvement and professional development". On the other hand, there were some teachers who believed that the main aim of TAS was "to keep teachers busy", and some others even believed that "the management was trying to control and judge teachers through this system", and that "the institution was planning to have a "pay for performance' or 'merit pay' system in the future."

Regardless of their demographic data, some teachers who had positive perceptions towards
TAS and thus committed to it and worked hard for it thought "the system was good in theory but did not work in practice" because (a) TAS was time consuming, (b) teachers did not have enough time, and (c) teachers had a heavy workload. The reasons teachers gave for not being committed to TAS were quite similar: teachers having excessive workloads, not having enough time and, additionally, the scheme's being imposed rather than self-initiated.

Nearly half of the teachers, except the Turkish teachers with less than three years of experience, felt no professional improvement due to TAS as they either had not done anything for TAS or had just done it for the sake of doing. Teachers who felt no improvement felt pressure, panic, frustration, demotivation and demoralisation instead. An experienced Turkish teacher expressed her worries in these words: "There were many things to do and very little time... My priority was preparing my lessons, teaching in class, exam marking, and that sort of things, so I couldn't give much time for TAS target, but still I felt like a little kid who didn't do her homework in time". On the other hand, the other half of the teachers felt professional improvement, and were motivated and happy due to TAS.

The teachers also made some suggestions for improvement. Half of the teachers suggested that any teacher who participates in TAS should have reduced timetables. Again, half of the teachers believed that such schemes should be optional if the aim is self-development.

It is important to note here that the way the appraisers defined the perception of the teachers in the group they appraised seems to be parallel to what the teachers said in the interviews. Almost all appraisers noted that teachers' perceptions could be broadly classified into several views: those who take it as a burden and have a negative view, those who are happy that they are doing it and have a positive view, and those who do it just because they have to and as it is another institutionalised duty. An appraiser, while talking about the teachers with a negative view, said, "Most teachers in my unit kept complaining. They said they already had so many things to do and never had enough time for TAS." This not only supports the data gathered from the teacher interviews but also shows that appraisers were aware of the teachers' perceptions 
of TAS. This means that there was a kind of close interaction between the teachers and the appraisers.

All in all, although it is difficult to say that teachers' perceptions of TAS changed considerably through their exposure to the system for the first cycle, the analysis of the results showed that the perceptions of some teachers, especially qualified Turkish ones with more than three years of experience, had changed from positive to negative after experiencing the scheme for some time as a result of the difficulties like time constraints and heavy teacher workload.

\section{Discussion}

The findings of the study revealed that ELT teachers' perceptions of TAS, carried out in an English language school at a university in Turkey, could be broadly classified into positive and negative views, although there were also some teachers who were not very sure of their attitude but participated in the scheme just because they had to as an institutionalised requirement. Although a big majority of teachers perceived the aim of TAS as awareness raising, self-evaluation, self-improvement and professional development, they believe that the TAS briefing session could not reach its aim as they were not clear about these aims after the briefing. Half of the teachers did not agree that they had improved themselves professionally by the help of TAS, as they could not be committed to the scheme due to various factors like time constraints and heavy workload or just because they did not believe in the necessity or the value of the system. On the other hand, the other half of the teachers, particularly Turkish teachers with less than three years of experience, felt that they had improved themselves professionally by the help of TAS. However, around 10-15 teachers who were mainly qualified Turkish teachers with more than three years of experience changed their attitude towards TAS from positive to negative as a result of experiencing the scheme for more than a semester on account of the difficulties that they expressed they had due to the heavy teacher workload. As to the native English speakers, who comprised one-fifth of our sample population (10 in number), we found the majority of them started the scheme with some questions in mind regarding the efficiency of such a system. Parallel to this, after the completion of the first cycle they said they had felt little or no professional improvement due to TAS.

A comparison of the findings of this study with those of some other similar research studies requires mentioning. We should note here that the appraisal system has a relatively short history in the ELT environment; therefore, very few related studies have been found during the review of literature. The latest literature on teacher development, especially in the ELT context, supports the findings of our study. Davis (1999) mentions that if a person with a higher status gets involved in the teacher development group activities, both the teachers and the line managers feel uncomfortable. Therefore, teachers prefer to keep the line managers off the class if the aim is 'development' rather than 'assessment'. Crooks (1997), on the other hand, discusses both the positive and the negative aspects of the role of administration of foreign language teachers, and suggests administrative support for teacher development as an important means to improvement. Finally, Casey, Gentle, and Bigger (1997) touch upon similar problems while talking about 'the professional development' model of teaching appraisal applied in Australia.

Other research studies on teacher appraisal systems conducted in different parts of the world, including Texas and North Carolina in the USA, various parts of Britain, Hong Kong, New Zealand, Japan and Australia, mostly revealed results parallel to what we found in our research. For example, the overwhelming majority of the interviewees (teachers from schools within one British local education authority) mentioned the time consuming factor of the process just like the teachers in our context. However, those teachers felt they had been well trained to participate in the process (Kyriacou, 1995), unlike the teachers in our study.

It is interesting to see that the majority of the teachers in our study did not talk about the positive aspects of TAS, unlike the teachers in other similar studies conducted in USA. Stacey (1988) carried out a research study to evaluate the effectiveness of the North Carolina Teacher Performance Appraisal System (TPAS). According to the findings of this 
study, although teachers tended not to evaluate the formative aspects and the implementation of TPAS very positively, they all perceived the system as contributing at least moderately to improve teaching. Another study conducted by Clift (1989) on the English teachers' perception of the Texas Teacher Appraisal System (TTAS), also revealed that almost all teachers believed that TTAS had got them to reflect on their teaching. However, the most frequently mentioned negative aspect of the system was similar to the findings of our study. Teachers in TTAS thought that they could stage or rehearse their teaching performance for the evaluators and that much depended on the relationship between the teacher and the appraiser. As mentioned in our study as well, the importance of school climate and the supportive but not directive managers was also expressed by the teachers who participated in the teacher appraisal system in Hong Kong (Mo, 1998).

Another finding of a study on the same subject which supports the results of this study is from a research project carried out by Turner and Clift in 1988 in eight schools which had their own appraisal schemes. The researchers report that: (i) teachers vary in how positive they are, from those who are highly enthusiastic to those who are merely lukewarm, (ii) some teachers took a very cynical view, seeing appraisal as a way of manipulating staff, whilst others saw it as a 'bandwagon' - the latest fashion to be involved with, and (iii) looking into the positive and negative views of appraisal, many teachers' perception of appraisal changed as a consequence of experiencing the system. However, the way the teachers' perceptions changed in that context was just the opposite of what has been found in our study, where the teachers' perceptions changed from positive to negative as a result of experiencing the system. On the other hand, both studies found that people who had been strongly opposed to appraisal did not seem to change their views significantly at the end of the process.

\section{Suggestions}

First of all, any teacher appraisal scheme demands quite extensive time and effort on the part of the appraisee in order to work to reach the targets that they have set for their professional self-improvement. Therefore, when teachers are asked to participate in such a demanding scheme on top of their responsibilities as full-time teachers of English (e.g. lesson preparation, homework and exam marking, exam and material production, and actual classroom teaching), their initial reaction could be negative. Even though some are not against the idea and think that it is very beneficial for them in order to improve professionally, such worries related to the time constraints may make them develop negative ideas about the system, which may eventually decrease their productivity.

The second danger of having a negative start for such a scheme can be the failure of explaining the real aims of the system by clarifying how the results will be or could be used in the near or distant future. If teachers are left with some questions in mind regarding the above-mentioned issues, it is possible that they could foster some scepticism about the benefits of the system for their self-development.

To avoid an unfortunate start, institutions could be advised to take some actions to clarify the real objectives and goals through some briefings. These briefings should also inform the appraisees of all the areas related to the appraisal scheme they would participate in, without leaving any ambiguity in their minds.

On the other hand, in order to administer a fruitful ELT teacher appraisal scheme, the institutions should spend some effort in encouraging the teachers to participate in the system by making it attractive for them, rather than making it compulsory and imposing it.

One way of doing so could be through activities showing appreciation to the people who have already worked hard for the system and who have proven to be successful in reaching the quality targets they set for themselves. The nature of this appreciation could vary from thanking these teachers by means of providing a certificate to publishing their names and studies in the school magazine, thus promoting them in the areas they have shown interest in. However, in order to be able to base the promotion of the training system on the outcomes of the appraisal scheme, the 
institution should have no doubts as to the standards and the quality of the appraisers. This would, eventually, require careful appraiser selection and training.

The focus of this study was the English language teachers' perceptions of a Teacher Appraisal Scheme and how they think this system contributes to their professional development. However, researchers eventually need to investigate whether positive teacher perception and acceptance of such systems would result in improved student learning in an English language teaching/learning context.

\section{Acknowledgements}

We would like to thank Greta MorineDershimer, the Editor, and the Teaching and Teacher Education reviewers for their comments on the earlier version of this paper.

\section{Appendix A. Initial questionnaire for the teachers}

Please answer the following questions on the teacher appraisal scheme that you are currently involved in by choosing the best option for you.

1. Which of the following areas does the target that you have set for the Teacher Appraisal Scheme fall into?
a) Grammar teaching
b) Skills teaching
c) Classroom management
e) ELT
d) English language
g) EAP
f) $\mathrm{ESP}$
h) Others (Please specify)

2. Does your target require a type of classroom observation?
a) Yes
b) $\mathrm{No}$

If your answer to 'question 2' is 'yes', what type of an observation is it?
a) by the group leader or teacher trainer
b) by a critical friend
c) by another person (Please specify)..........
d) self (through video or audio recording
e) others (Please specify)

3. How long will it take for you to achieve your first target?
a) a few weeks to two months
b) a semester
c) four to five months
d) an academic year
e) longer

Please answer the following questions briefly.

4. What do you think about being involved in this scheme?

5. Do you think there will be some changes in your teaching and performance as a result of being involved in this scheme? If yes, in what ways?

Finally, please fill in the following blanks.

Age: ................. Sex: .................. Nationality:

ELT experience: ............. years .............. months

BA degree subject(s):

Any post graduate qualifications (if relevant): 


\section{Appendix B. Teacher interview questions}

Please answer the following questions on the teacher appraisal scheme that you are currently involved in by choosing the best option for you.

1. Which of the following areas does/do the target(s) that you have set for the Teacher Appraisal Scheme fall into?
a) Grammar teaching
b) Skills teaching
c) Classroom management
d) English language
e) ELT methodology
f) $\mathrm{ESP}$
g) EAP
h) Others (Please specify)

2. If your target(s) required a type of classroom observation, what type of an observation was/were it/they?
a) by the group leader
b) by a teacher trainer
c) by a critical friend
d) by another person (Please specify)
f) others (Please specify)......
e) self (through video or audio recording)
g) irrelevant

3. How long did it take for you to achieve your first target?
a) a few weeks to two months
b) a semester
c) still goes on

4. How many targets have you been able to work on since October 1995 ?
a) one
b) two
c) three
d) more

Please answer the following questions as in detail as possible.

5. Have you ever been involved in an appraisal scheme elsewhere? Any comments?

6. What is the aim of TAS in this institution? What do you think about it?

7. How do you think the teachers should be prepared for such a scheme?

8. What do you think about the meetings (target setting and target review) with the appraiser? (Consider the physical conditions of the room, the timing, any disturbance and/or interruptions etc.)

9. What do you think about your degree of commitment to TAS as an appraisee up to now?

10. How do you think the results of TAS will be beneficial for the Management?

11. Do you think there has been any change/improvement in your morale, motivation and teaching techniques since the beginning of this academic year when you started to be involved in TAS? Why/Why not?

12. What do you think an ideal EFL teacher appraisal scheme should be like so that it could be beneficial both for the teacher and the institution to the utmost? 
Any other comments on 'TAS' that you wish to add:

Finally, please fill in the following blanks.

Age:

Sex:

Nationality:

ELT experience:

years months

BA degree subject(s):

Any post graduate qualifications (if relevant):

\section{Appendix C}

Question \#11: Do you think there has been any change/improvement in your morale, motivation and teaching techniques since the beginning of this academic year when you started to be involved in TAS? Why/Why not?

Codes for question \# 11: (The impact of TAS on teachers - any changes? / improvement?)

1: no improvement as I haven't done anything/much

2: no improvement as I have done it just for the sake of doing it

3: felt pressure / panic / frustration / demotivation / demoralization / burden

4: some improvement

5: improvement

6: improvement only through the targets I've chosen myself (not forced)

7: felt motivation / happiness

8: development due to MA/dip., not TAS

Two dimensional matrices for the answers to question \# 11 in teachers' interview:

\begin{tabular}{|c|c|c|c|c|c|c|c|}
\hline $\begin{array}{l}\text { Strata } \\
\text { Codes }\end{array}$ & $\begin{array}{l}\text { Foreign }(-) \\
(\mathrm{n}=4)\end{array}$ & $\begin{array}{l}\text { Foreign }(+) \\
(\mathrm{n}=6)\end{array}$ & $\begin{array}{l}-3 \text { (COTE) } \\
(\mathrm{n}=4)\end{array}$ & $\begin{array}{l}3-9(-) \\
(\mathrm{n}=8)\end{array}$ & $\begin{array}{l}3-9(+) \\
(\mathrm{n}=13)\end{array}$ & $\begin{array}{l}+10(-) \\
(n=5)\end{array}$ & $\begin{array}{l}+10(+) \\
(\mathrm{n}=10)\end{array}$ \\
\hline 1 & 2 & 1 & & 3 & 4 & 2 & 1 \\
\hline 2 & & & & 1 & 4 & & 1 \\
\hline 3 & & 1 & 1 & 1 & 5 & & 1 \\
\hline 4 & & & 4 & 2 & 1 & & 2 \\
\hline 5 & & 1 & & 1 & 1 & 2 & 1 \\
\hline 6 & 2 & 1 & & & & & \\
\hline 7 & & & & 1 & 1 & 1 & \\
\hline 8 & & 2 & & 1 & 1 & & 3 \\
\hline
\end{tabular}




\section{References}

Brumfit, C., \& Mitchell, R. (1993). Research in the language classroom. London: MacMillan Publishers Ltd.

Casey, R. J., Gentle, P., \& Bigger, S. W. (1997). Teaching appraisal in higher education: An Australian perspective. Higher Education, 34(4), 459-482.

Clarke, M. A., Davis, A., Rhodes, L. K., \& DeLott Baker, E. (1998). Principles of collaboration in school-university partnerships. TESOL Quarterly, 32(3), 592-600.

Clift, R. (1989). Dogs, ponies, and the improvement of teaching: English teachers' perceptions of the Texas teacher appraisal system. Paper presented at the annual meeting of the American Educational Research Association, San Francisco, CA, March.

Crooks, G. (1997). What influences what and how 2nd language and foreign language teachers teach. Modern Language Journal, 81(1), 67-69.

Davis, P. (1999). What is teacher development?. Humanistic Language Teaching, $1,1$.

England, L. (1998). Promoting effective professional development in English language teaching. English Teaching Forum, $36(2), 18-23$.

Fraenkel, J. R., \& Wallen, N. E. (1993). How to design and evaluate research in education (2nd ed.). New York: McGraw-Hill Inc..

Goetz, J. P., \& LeCompte, M. D. (1984). Ethnography and qualitative design in educational research. Orlando: Academic Press Inc..

Krathwohl, D. R. (1998). Methods of educational and social science research: An integrated approach. New York: Addison Wesley Longman, Inc..

Kyriacou, C. (1995). An evaluation of teacher appraisal in schools within one local education authority. School Organisation, 15, 2.
Long, M. (1980). Inside the "black box": Methodological issues in classroom research on language learning. Language Learning, 30, 1-42.

Miles, M. B., \& Huberman, A. M. (1984). Qualitative data analysis: A sourcebook of new methods. Beverly Hills: Sage Publications.

Mo, K.W. (1998). School climate and the effectiveness of teacher appraisal in Hong Kong self-managing schools. Paper presented at the annual meeting of the American Educational Research Association, San Diego, CA, April.

Nunan, D. (1993). The teacher as researcher. In C. Brumfit, \& R. Mitchell, Research in the language classroom. London: MacMillan Publishers Ltd..

O'Sullivan, F., Jones, K., \& Reid, K. (1988). Staff development in secondary schools. London: Hodder and Stoughton.

Scribbins, K., \& Walton, F. (1987). Staff appraisal: In further and higher education. Bristol: The Further Education Staff College.

Stacey, D. (1988). Evaluation of the effectiveness of the North Carolina teacher performance appraisal system (TPAS). Paper presented at the annual meeting of the American Educational Research Association, New Orleans, LA, April.

Turner, G., \& Clift, P. (1988). Studies in teacher appraisal. London: The Falmer Press.

Wallace, M. (1991). Training foreign language teachers: A reflective approach. Cambridge: Cambridge University Press.

Wiersma, W. (1995). Research methods in education: An introduction. Boston: Allyn and Bacon.

Woodward, T. (1991). Models and metaphors in language teacher training: Loop input and other strategies. Cambridge: Cambridge University Press. 